\title{
GÊNESE E INCLUSÕES DAS ESMERALDAS DE SANTA TEREZINHA DE GOIÁS - GO
}

\author{
CARLITO LARIUCCI*, CIRANO ROCHA LEITE**, REGINA HELENA DE ALMEIDA SANTOS***
}

\begin{abstract}
GENESIS AND INCLUSIONS OF THE EMERALDS FROM SANTA TEREZINHA DE GOIÁS - GO The genesis of the emeralds from Santa Terezinha de Goias-GO remount to solutions of a pneumatolytic-metasomatic phase having as the chromium donor source metamorphosed basic-ultrabasic rocks (various schists), whose chromipherous mineral is spinel, found also as a protogenetic inclusion. The mineral inclusions identified by means of X-ray diffraction (powder method), optical microscopy and electron microprobe, were spinel, pyrite, pyrrhotite, dolomite, magnesian siderite, talc, mica (biotite, phlogopite), emerald, quartz, talc-pyrophyllite, rutile, halite and/or sylvite. The presence of biphasic inclusions varying in size and form was also observed. Among theses inclusions, pyrrhotite and/or halite, magnesian siderite and talc-pyrophyllite were detected for the first time in the emeralds from Santa Terezinha de Goiás. The presence of a great quantity of spinel constitutes one of the main characteristics of these emeralds.
\end{abstract}

Keywords: Inclusions, spectroscopy, X-ray difraction, emerald, Santa Terezinha (GO).

\begin{abstract}
RESUMO Neste trabalho é feita uma caracterização das esmeraldas de Santa Terezinha de Goiás por meio de sua gênese e inclusões minerais. A gênese dessas esmeraldas remonta as soluções da fase pneumatolítica-metassomática tendo, como fonte doadora de cromo, rochas básicas-ultrabásicas metamorfisadas (diversos xistos) cujo mineral cromífero é o espinélio, encontrado também como inclusão protogenética. As inclusões minerais, identificadas por meio de difração de raios $\mathrm{X}$ (método do pd), microscopia óptica e mlcrossonda eletrônica, foram: espinélio, pinta, pirrotita, dolomite, siderite com Mg, talco, mica(biotíte/flogopite), esmeralda, quartzo, talco-pirofilita, rutilo, halite e/ou silvita. Foi observada, também, a presença de inclusões bifásicas de tamanhos e formas bastante variadas. Destes inclusões, a pirrotita, a silvita e/ou halita, a siderite com $\mathrm{Mg}$ e o talco-pirofilita foram detectados pela primeira vez em esmeraldas de Santa Terezinha de Goiás. A presença de grande quantidade de espinélio constitui uma das principais características dessas esmeraldas.
\end{abstract}

Palavras-chaves: Inclusões, espectroscopia, difração de raios X, esmeralda, Santa Terezinha (GO).

INTRODUÇÃO Desde 1982, um ano após a descoberta do Garimpo de Santa Terezinha de Goiás, alguns trabalhos específicos foram realizados, uns enfatizando a geologia local e regional, tais como os de Ribeiro \& Sá (1983), Ribeiro Filho \& Lacerda Filho (1985) e Costa (1986), enquanto outros destacam as características mineralógicas (inclusões), como os de Hänni \& Kerez (1983), Cassedane \& Sauer (1984), Barros (1984), Schwarz \& Mendes (1985) e Miyata et al. (1987). Entretanto, foi observado que, nos trabalhos anteriores, não está clara a questão da gênese das esmeraldas de Santa Terezinha de Goiás. Este trabalho visa fornecer resultados que contribuam com informações para as hipóteses formuladas para a sua gênese, além de apresentar um estudo amplo sobre as inclusões encontradas nessas esmeraldas.

SITUAÇÃO GEOGRÁFICA E GEOLÓGICA Localização e acesso $O$ garimpo de esmeraldas de Santa Terezinha de Goiás, está situado no centro-oeste goiano, distando de Goiânia cerca de $310 \mathrm{~km}$. Seu ponto central apresenta longitude e latitude aproximadas de $49^{\circ} 20^{\prime} \mathrm{W}$ e $14^{\circ} 55^{\prime} \mathrm{S}$ (Fig. 1). Tomando-se a rodovia asfaltada GO-080, num percurso de 95 km de Goiânia, atinge-se a BR-153, na altura do km 1.157.

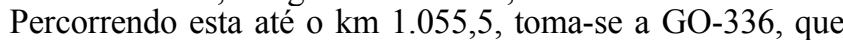
conduz a Itapaci por uma distância de $20 \mathrm{~km}$. Seguindo rumo a Pilar de Goiás pela GO-154 alcança-se essa cidade após um percurso de $30 \mathrm{~km}$ e segue-se por esta rodovia, não asfaltada, por $52 \mathrm{~km}$ até Santa Terezinha de Goiás, seguindo-se, então, mais $21 \mathrm{~km}$ até a Fazenda São João, por estrada municipal, onde se localiza/o garimpo, hoje denominado Campos Verdes. É pdssível chegar também ao garimpo partindo da BR-153, através da GO-439, via Hidrolina e GO-465, passando por Campinorte.

\section{Síntese da geologia regional A geologia do garimpo de}

Santa Terezinha de Goiás é considerada por Barbosa et al. (1969) como compreendida no Grupo Araxá, sendo formada por duas seqüências: uma basal, composta de micaxisto a duas micas, finas e grossas, com intercalações de quartzitos micáceos, e outra de calcoxistos, com intercalações de calcário.

De acordo com Ribeiro Filho (1978), a área estaria enquadrada dentro de uma seqüência vulcano-sedimentar do tipo cinturões móveis, bordejando núcleos cratônicos, representados pelos terrenos granítico-gnáissicos migmatizados que ocorrem na região. Essa seqüência, de idade provável proterozóica-inferior-média, apresenta como características principais: direção estrutural predominante NE e uma extensão superficial de várias centenas de quilômetros de comprimento, com largura que varia até dezenas de quilômetros.

Souza \& Leão Neto (1984) denominaram de Seqüência Santa Terezinha ao conjunto vulcano-sedimentar de baixo grau metamórfico, posicionado a norte da cidade homônima. Esta encontra-se inserida numa calha de direção preferencial NE - S W, com bifurcação para sul, possuindo largura média de $6 \mathrm{~km}$. E balizada, a sudoeste, por uma estrutura dômica de forma grosseira elíptica, constituída de gnaisses grossos (domo da Serra de Santa Cruz); a noroeste, é limitada por rochas graníticas gnaissificadas, onde se demarca um corpo de granito pórfiro (Granito São José de Alegre); a sudoeste, encontra-se com uma associação gnáissico-anfibolítica-calcossilicática (Fig. 2). Seus limites longitudinais encontram-se fora da área cartografada por Souza \& Leão Neto (1983), mostrando continuidade física para sul com a Seqüência Mara Rosa, de Ribeiro Filho (1981) e para norte com o Grupo Araxá (Sabóia 1979 e Drago et al. 1981).

Geologia local Ribeiro \& Sá (1983) consideraram que a área do garimpo apresenta, como embasamento, uma rocha

\footnotetext{
* Departamento de Física, Universidade Federal de Goiás, Campus II, Caixa Postal 131, CEP 74000, Goiânia, GO, Brasil

** Instituto de Química de Araraquara, UNESP, Caixa Postal 174, CEP 14800, Araraquara, SP, Brasil

*** Instituto de Física e Química de São Carlos, Universidade de São Paulo, Caixa Postal 369, CEP 13560, São Carlos, SP, Brasil
} 


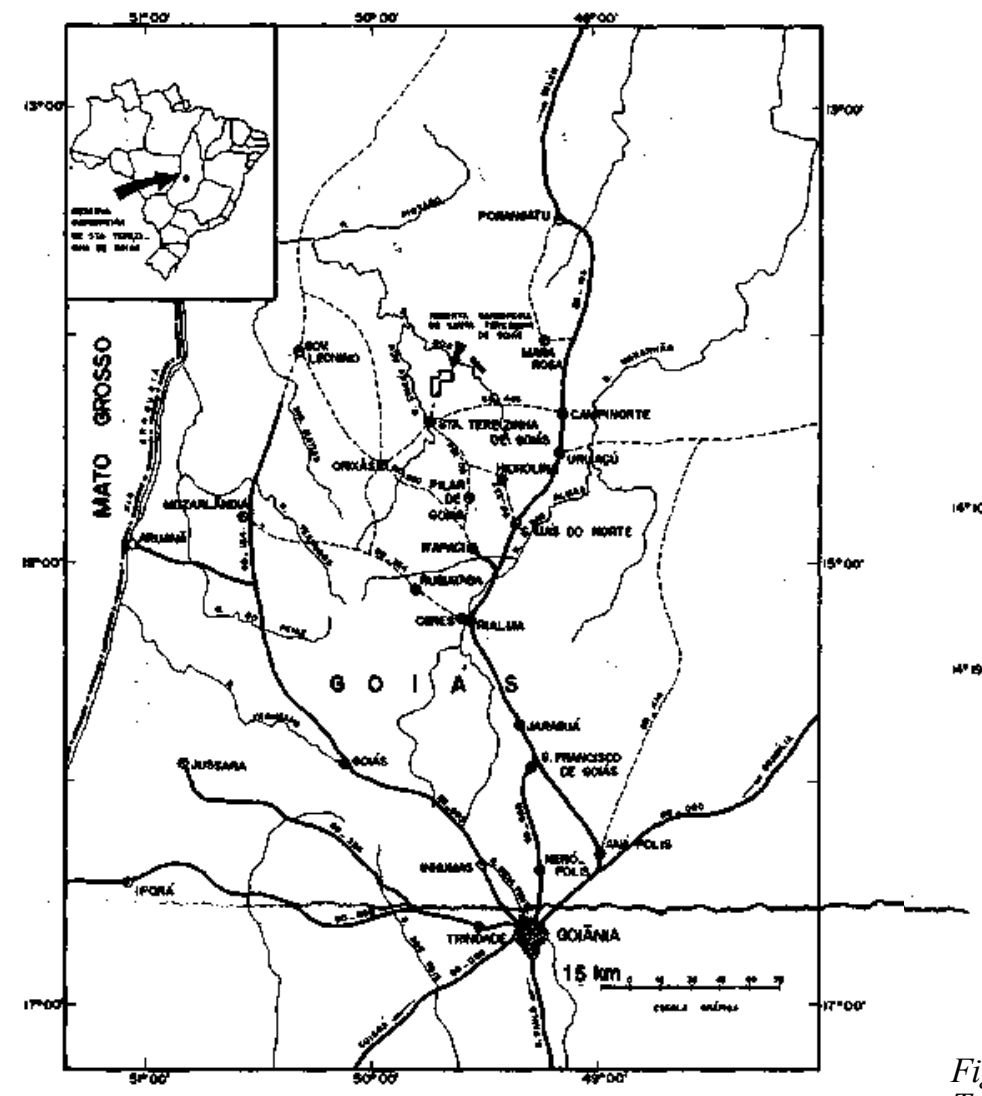

Figura 1 - Mapa de Localização da reserva garimpeiro de Santa Terezinha de Goiás (DNPM/VI Distrito Regional, Projeto Ouro Goiás 1985)

Figure 1 - Localization map for the Santa Terezinha de Goiás emerald deposit (DNPM-VI Distrito Regional - Projeto Ouro Goiás 1985)

biotito-gnáissica, que se encontra em contato com uma seqüência de rochas vulcano-sedimentares, com o termo ácido representado por rochas metavulcânicas, de composição provavelmente dacítica; os termos ultrabásicos da seqüência seriam representados pelos seus equivalentes retrometamorfisados, tais como talco-clorita xisto carbonátíco (biotitíto) e tremolita-clorita xisto. Subordinadamente, ocorrem leitos de metacherts ferríferos, manganesíferos, quartzitos ferruginosos e metamargas. A mineralização, segundo os autores, obedece a um controle litológico e ocorre, principalmente, no talcoclorita xisto e/ou bolsões de biotitito ou mesmo no veio quartzo-feldspátíco, corte ou não aquelas litologias.

ANÁLISE DAS INCLUSÕES E DE ROCHAS ENCAIXANTES POR DIFRAÇÃO E FLUORESCÊNCIA DE

RAIOS X As amostras foram coletadas em duas etapas. A primeira visita realizada ao garimpo de Santa Terezinha de Goiás foi efetuada em setembro de 1985. Nesta visita foram conseguidos lotes de amostras de dois pontos do Trecho Velho, de quatro pontos do Trecho Novo, um ponto do Trecho do Netínho e um ponto do Trecho do Antônio Rosa (Fig. 3). A segunda visita ocorreu um ano após a primeira, durante a qual foram obtidos lotes de amostras de um ponto do Trecho do José Maria e de dois pontos do Trecho Novo.

Às amostras abrangeram todos os trechos em produção, no período em que foram coletadas. Assim, foi possível dispor de aproximadamente 70 amostras, quase todas sem valor comercial (esmeraldas com inclusões ou defeitos), algumas com valor comercial (esmeraldas lapidáveis) e aproximadamente o mesmo número de amostras de rochas encaixantes.

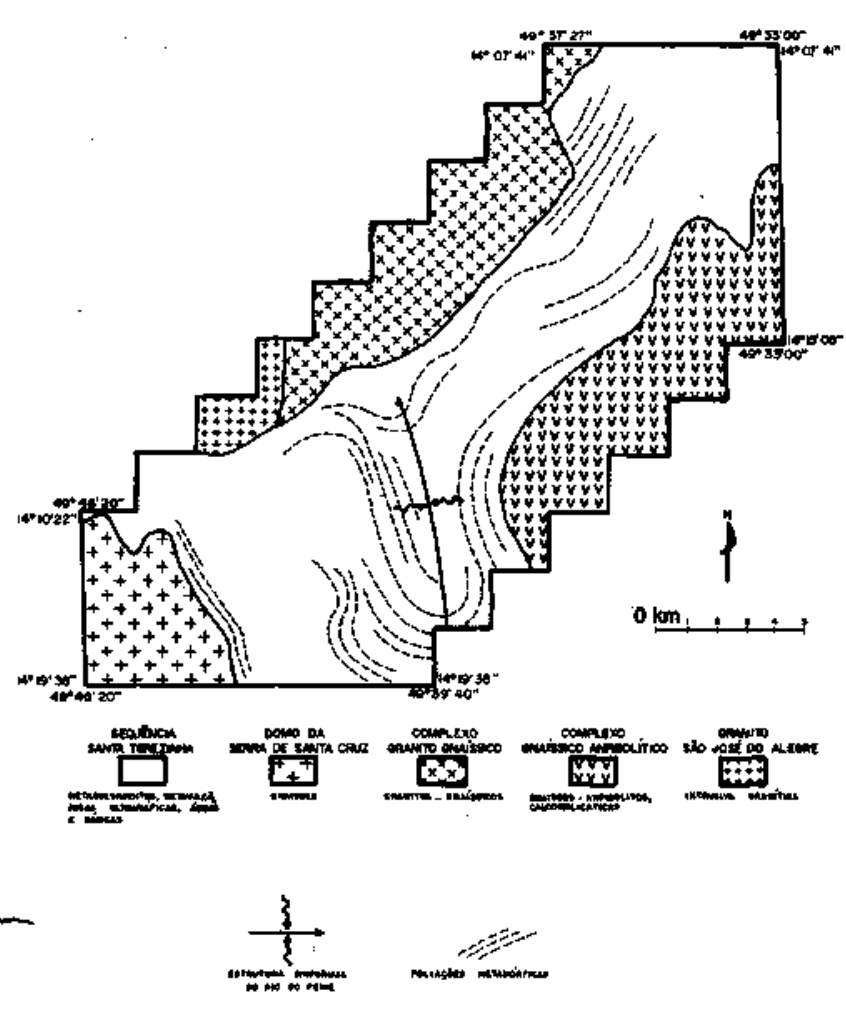

Figura 2 - Mapa geológico da região dos Garimpos de Santa Terezinha de Goiás mostrando a distribuição da Seqüência Santa Terezinha (simplificado e modificado do mapa 1:25.000 de Souza \& Leão Neto 1983)

Figure 2 - Geologic map of the Santa Terezinha de Goias-GO emerald deposit showing the Santa Terezinha sequence's distribuitíon (modified and simplified from the map 1:25,000 of Souza \& Leão Neto 1983)

Estudos das inclusões por fluorescência e difração de raios X Para estudo das inclusões por fluorescência de raios $X$, foi usada uma microssonda eletrônica e do EDS (Energy Dispersive System X-ray microanaly-LINK Systems), sendo este acoplado à microssonda. Com este conjunto, é possível obter a análise semiquantitativa da amostra.

As lâminas delgadas utilizadas nesta técnica de análise foram preparadas da seguinte forma: imersão das amostras em uma resina (araldite), por serem pequenas, seguida de laminação e fixação em lâminas de vidro apropriadas. A seguir, sofreram polimento grosso com carbeto de silício, até uma espessura de aproximadamente $200 \mu \mathrm{m}$, e fino com pasta de diamante. E, por fim, as mesmas foram metalizadas com carbono.

Após a preparação das amostras, foi possível obter 80 espectros relativos às inclusões e aos hospedeiros.

Os espectros de EDS mostram a presenca de elementos compatíveis com os presentes nos minerais de espinélio, quartzo, siderita com $\mathrm{Mg}$, esmeralda, dolomita, flogopita, talco-pirofilita, biotita, talco e carbonates.

A difração de raios $\mathrm{X}$ foi realizada em um difratômetro de pó HZG4B (JENA) com radiação CuKct, velocidade de varredura $2 \%$ min em $2 \theta$, em câmara de Guinier, usando-se também a radiação $\mathrm{CuKa}$ e 10 horas de exposição.

Com estas técnicas de policristal, foi possível identificar as inclusões de pirita, talco e pirrotita.

Estudo das rochas encaixantes por difração de raios X Na análise das rochas encaixantes foram utilizados um goniômetro horizontal de raios X Philips, um difratômetro de pó HZG4B (JENA) e câmara de Debye-Scherrer. 


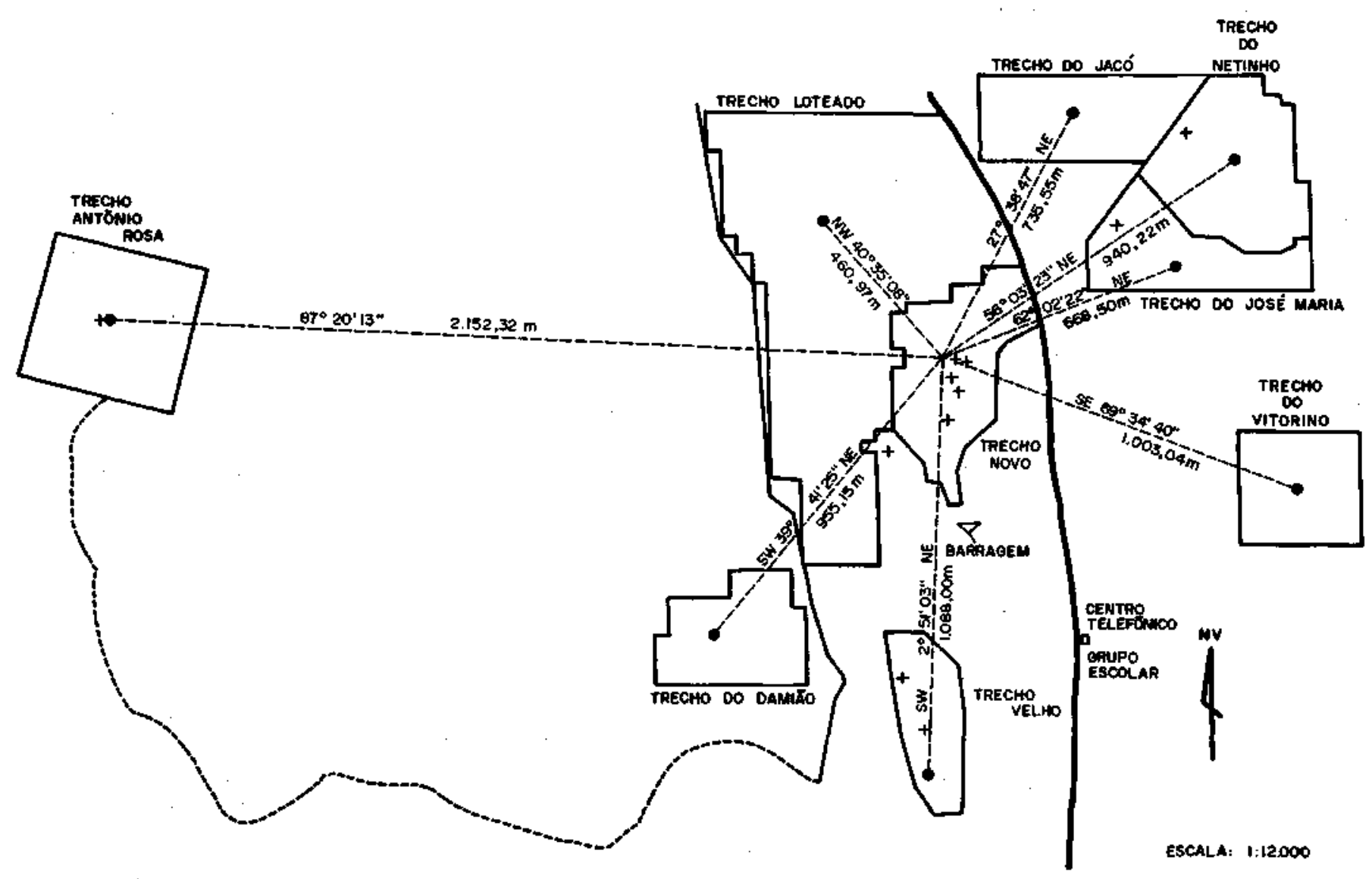

Figura 3 - Mapa de articulação dos trechos do Garimpo de Santa Terezinha de Goiás e localização dos pontos (+) onde foram coletadas as amostras (modificado de DNPM VI Distrito, Projeto Ouro Goiás 1985)

Figure 3 - Articulation map os the places where the samples were colected and the localization site (+) in the Santa Terezinha de Goias-GO emerald/deposit

Os difratogramas obtidos foram analisados como demonstrativos da presença de dolomita, magnesita, talco, flogopita/biotita, quartzo, moscovita, turingita e clorita.

Os resultados obtidos pela câmara de Debye-Scherrer, para algumas amostras, são concordantes com os expostos anteriormente.

CONSIDERAÇÕES SOBRE A GÊNESE A teoria mais difundida e com maior aceitação sobre a gênese de depósitos esmeraldíferos em todo o mundo atribui a formação da gema à substituição do $\mathrm{Al}^{3+}$ pelo $\mathrm{Cr}^{3+}$, na estrutura cristalina do mineral berilo $\left(\mathrm{Al}_{2} \mathrm{Be}_{3} \mathrm{Si}_{6} \mathrm{O}_{18}\right)$.

Para que tal processo ocorra, é necessário, portanto, que uma solução transportadora de berilo encontre um ambiente em que haja disponibilidade de $\mathrm{Cr}^{3+}$, elemento responsável pela cor verde da esmeralda.

Essa teoria tem encontrado respaldo nas jazidas russas (Urais), em Leidsdorp (Transvaal) e no complexo de Gravellote-mica (Kaapvaal), segundo Griffon et al. (1967) e Couto \& Almeida (1982), o mesmo ocorrendo na Colômbia (Johnson 1961 e Pogue 1916).

No Brasil, os exemplos mais conhecidos e estudados são os garimpes de Carnaíba (BA) e Santa Terezinha de Goiás que, de uma maneira geral, também se enquadram na teoria acima. Em Carnaíba, de acordo com dados da literatura, as esmeraldas ocorrem nas proximidades do Granito de Carnaíba, em filões de flogopita-biotita xistos, encaixados em serpentinitos, especialmente em zonas mais fraturadas, geradas pela ação metassomática de pegmatites injetados a partir da massa granítica. As esmeraldas de Santa Terezinha de Goiás ocorrem, além de nos filões de flogopita-biotita xistos, também nos veios carbonáticos, ambos nas proximidades do Granito São José de Alegre (Costa 1986, Schwarz 1986).

A semelhança entre as esmeraldas de Santa Terezinha de Goiás e as colombianas é atribuída à ocorrência de ambas em veios carbonáticos, disto provém o grande número de inclusões carbonáticas observadas nas mesmas. Para Schwarz (1986), a falta de inclusões trifásicas tipo sólido-líquido-gás (slg), consideradas características para esmeraldas formadas em ambiente hidrotermal (por exemplo, Colômbia e Swat-Paquistão), indica que as esmeraldas de Santa Terezinha de Goiás remontam às soluções da fase pneumatolítico-metassomática. Segundo Costa (1986), a gênese pode estar relacionada tanto às soluções pneumatolíticas de granitos subjacentes, como às transferência de material por deformação diferencial a partir de rochas circunvizinhas (vulcânicas ácidas etc.). Uma fonte mista, isto é, soluções residuais de granito, associadas à fase de metamorfismo, pode também ser admitida.

Após o estudo das inclusões nas esmeraldas de Santa Terezinha de Goiás, é possível concluir que o espinélio é a fonte doadora de cromo para a esmeralda. Esta hipótese corrobora às admitidas por Schwarz (1986) e Ribeiro \& Sá (1983), que indicaram, como fonte doadora de cromo, rochas básicas-ultrabásicas metamorfisadas (diversos xistos).

INCLUSÕES As inclusões minerais predominam nas 
esmeraldas de Santa Terezinha de Goiás. Apresentam-se em quantidades e formas bastante variadas, que são descritas a seguir.

Halita e/ou silvita Foi notada, em algumas amostras, a presença de cristais cúbicos e transparentes (Foto 1) ao serem observadas no microscópio com luz transmitida. Com ou sem polarização, não foi observada nenhuma alteração de cor nesta inclusão, sendo esta completamente isotrópica. Uma vez que essas características são as mesmas de halita e silvita, foi concluída sua presença.

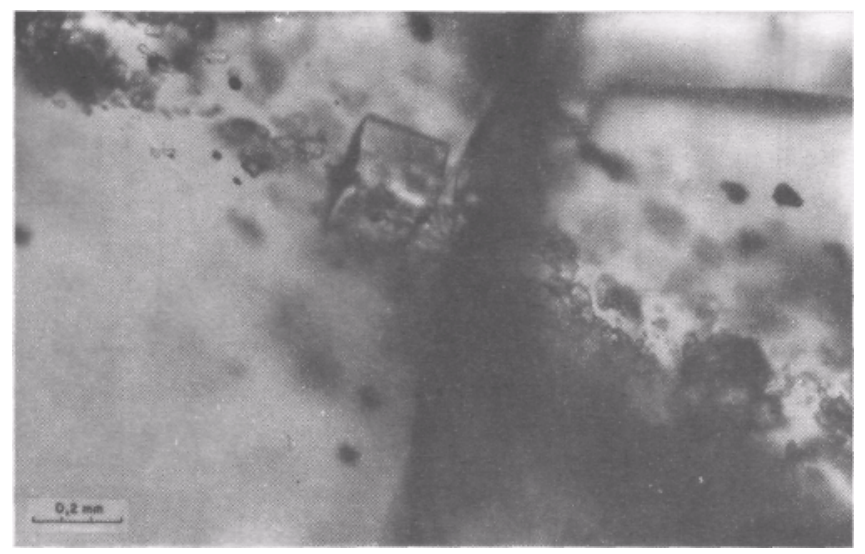

Foto l-Esmeralda com inclusão de halita elou silvita Photo 1 - Emerald with halite and/or silvite inclusion

Rutilo A ocorrência de inclusões de rutilo é muito pequena. De todas as amostras estudadas, somente uma apresentou inclusão deste mineral, sob forma prismática alongada ou curta e geralmente com geminação na forma de joelhos, com cor castanho-avermelhada escuro e brilho submetálico (Foto 2). O rutilo apresenta-se em cristais isolados e bem formados, distribuídos de uma maneira mais ou menos uniforme no cristal hospedeiro.

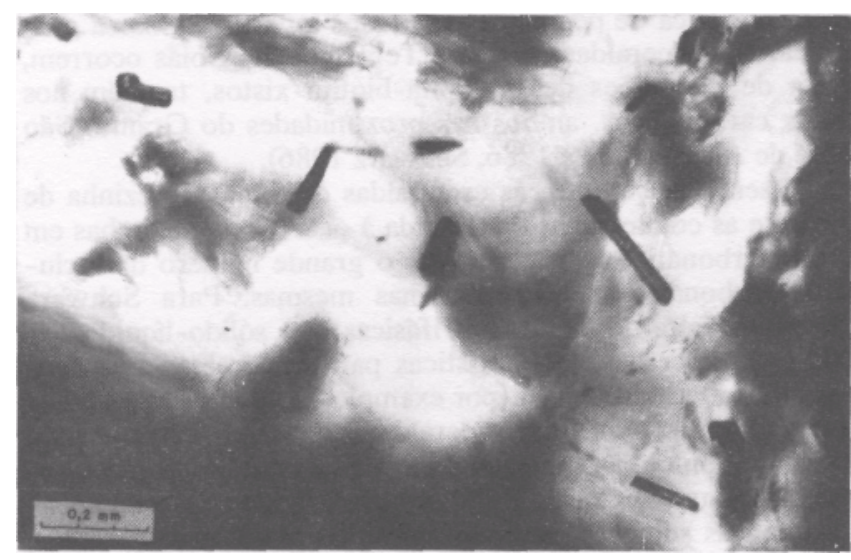

Foto 2 - Esmeralda com inclusões de rutilo

Photo 2 - Emerald with rutile inclusions

Esmeralda e quartzo Ocasionalmente, são observados, como mineral de inclusão, pequenos cristais de esmeralda. Podem ser reconhecidos devido a uma ligeira variação de cor em relação ao cristal hospedeiro (Foto 3 ). O mesmo ocorre com o quartzo, que foi identificado pela análise por microssonda eletrônica.

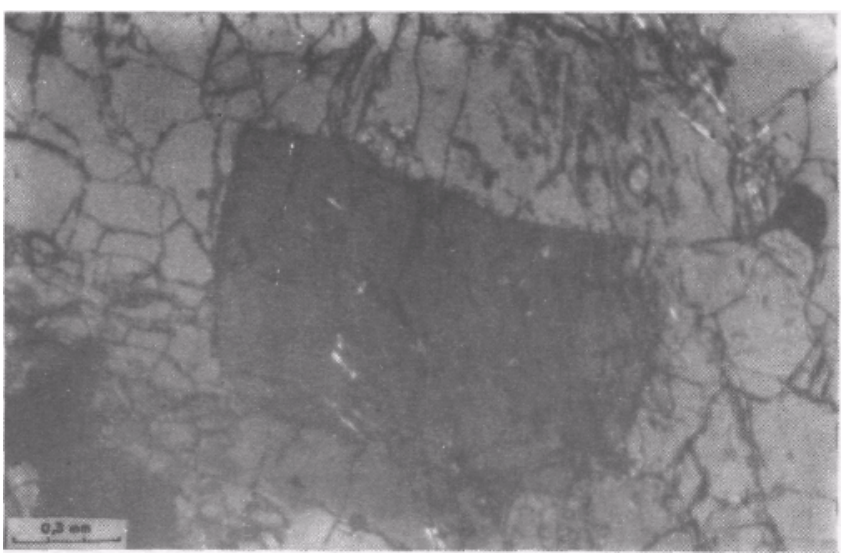

Foto 3 - Esmeralda com inclusão de esmeralda Photo 3 - Emerald with emerald inclusion

Talco e mica Em quantidades bem pequenas, são encontrados o talco e a mica (biotita, flogopita).

$\mathrm{O}$ talco é praticamente imperceptível sem o auxílio do microscópio, porém, com o auxílio deste, usando-se luz transmitida, é percebido pelos seus reflexos prateados (Foto 4).

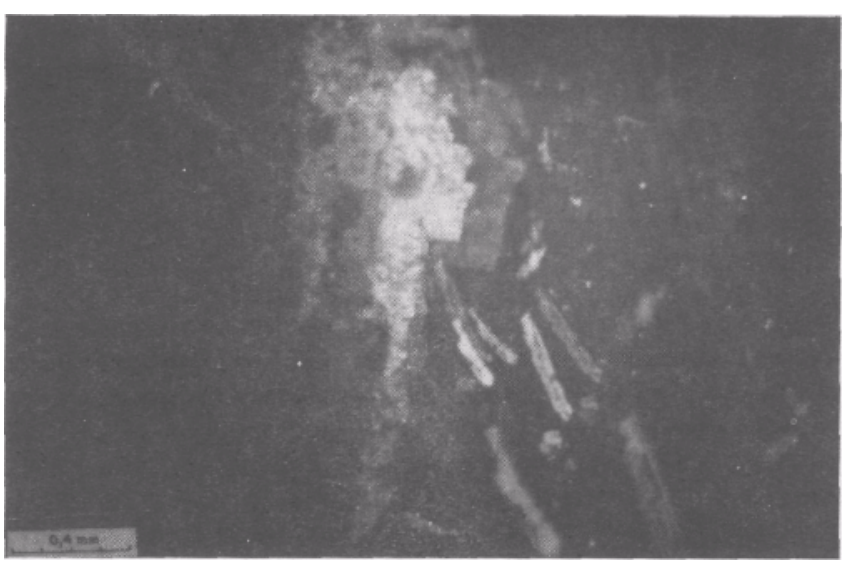

Foto 4-Esmeralda com inclusão de talco

Photo 4 - Emerald with talc inclusion

A composição química desta inclusão foi analisada em várias amostras com as mesmas características. Com a utilização de microssonda eletrônica, foi constatada a presença de Si, $\mathrm{Mg}$ e traços de Fe e Ni e, em algumas das amostras, também foi detectada a presença de $\mathrm{Al}$, caracterizando, assim, a presença de talco e talco-pirofilita respectivamente.

Por meio de difração de raios X, foi verificada a presença de duas reflexões cujas distâncias interplanares correspondem às raias mais intensas do talco, como pode ser observado na tabela 1, quando comparada com os valores tabelados JCPDS (1983).

Tabela 1 -Distâncias interplanares $(\AA)$ observadas e tabeladas para o talco

Table 1 - Interplanar distances $(\AA)$ observed and tabled for the talc

\begin{tabular}{|c|c|}
\hline d (observada) & d (JCPDS, 1983) \\
\hline 9,31 & 9,35 \\
\hline 3,10 & 3,12 \\
\hline
\end{tabular}


As micas podem se apresentar em cristais individuais ou, mais raramente, como concentração de agregados irregulares. Elas formam família caracterizada por uma série de propriedades comuns. Um dos meios de diferenciação é pela composição química. Os elementos químicos determinados nas análises realizadas foram $\mathrm{Al}, \mathrm{Si}, \mathrm{Mg}, \mathrm{K}$ e traços de $\mathrm{Fe}$ e, em outras amostras, um teor de Fe mais elevado foi determinado, o que levou à conclusão da possível presença de flogopita e biotita, respectivamente.

Carbonates Inclusões carbonáticas ocorrem em maior quantidade do que a mica e o talco. Apresentam-se em formas muito variadas, desde pequenos cristais irregulares e razoavelmente distribuídos sobre o cristal hospedeiro, até concentrações em algumas regiões da esmeralda (Foto 5a), e também cristalizadas em fendas (Foto $5 \mathrm{~b}$ ).

Dentre as inúmeras inclusões carbonáticas de origens proto, epi e singenéticas foi possível identificar a dolomita e a siderita com Mg.

Este resultado difere de Hänni \& Kerez (1983), que consideraram as inclusões carbonáticas como dolomita, e de Cassedanne \& Sauer (1984), que as interpretaram como uma solução sólida de calcita-dolomita.
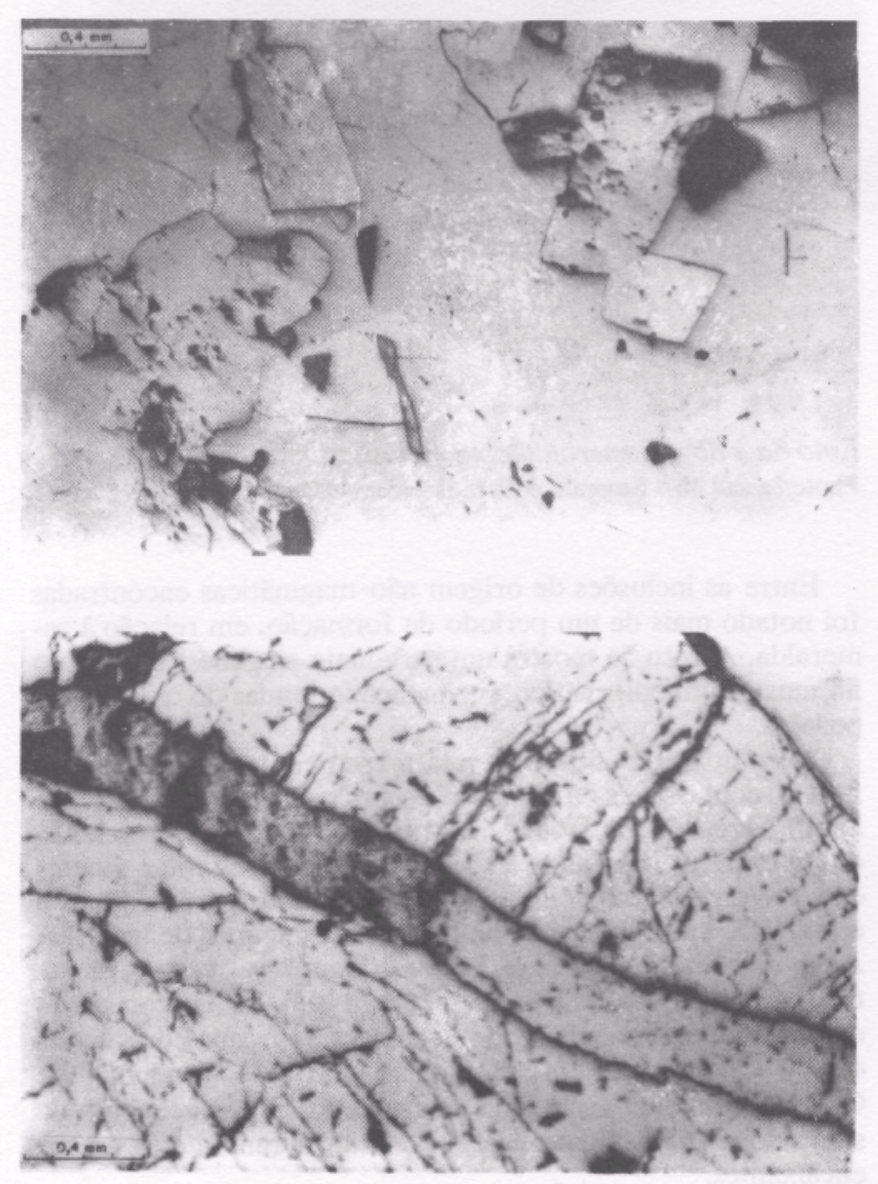

Foto 5 a e $5 b$ - Esmeralda com inclusões de carbonates Photos $5 \mathrm{a}$ and $\mathrm{Sb}$-Emerald with carbonate inclusions

Pirita e pirrotita $\mathrm{O}$ mineral de inclusão opaca mais freqüente que os carbonates é a pirita, que é identificada devido a forma cúbica bem desenvolvida de seus cristais (Foto 6). Além de observada por microscopia óptica, a sua presença foi confirmada por meio de difratometria de raios X, pelo método

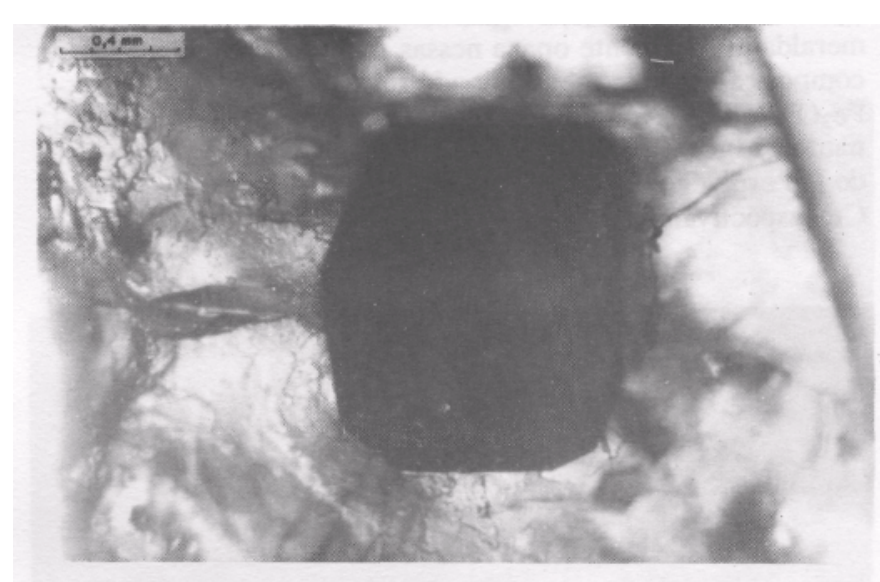

Foto 6 - Esmeralda com inclusão de pirita

Photo 6-Emerald with inclusion pyrite

do pó. Nas interpretações dos difratogramas foram obtidas, além das reflexões da esmeralda, mais seis reflexões correspondentes às mais intensas da pirita, com distâncias interplanares $\left(\mathrm{d}_{\mathrm{nk}}\right)$ observadas e comparadas com as tabeladas na JCPDS, mostradas na tabela 2 .

Tabela 2 - Distâncias interplanares $(K)$ observadas e tabeladas para a pirita

Table 2 - Interplanar distances $(\AA)$ observed and tabled for pyrite

d (observada)
3,105
2,706
2,423
2,209
1,918
1,631

$\mathrm{d}(\mathrm{JCPDS}, 1983)$
3,128
2,709
2,423
2,2118
1,9155
1,6332

A presença de mais um sulfeto de ferro, além da pirita, foi observada nos resultados experimentais obtidos pela difração de raios X. Após análise detalhada dos difratogramas, foi verificado que as distâncias interplanares $\left(\mathrm{d}_{\mathrm{hkl}}\right)$, correspondentes às reflexões ainda não explicadas, eram compatíveis com os $\mathrm{d}_{\mathrm{hkl}}$, das reflexões mais-intensas da pirrotita, como pode ser observado na tabela 3 .

Tabela 3 - Distâncias interplanares (Å) observadas e tabeladas para a pirrotita

Table 3 - Interplanar distances (A) observed and tabled for pyrrhotite

\begin{tabular}{cc}
\hline d (observada) & d (JCPDS, 1983) \\
3,01 & 2,98 \\
2,67 & 2,65 \\
2,00 & 2,06 \\
1,74 & 1,72 \\
\hline
\end{tabular}

Espinélio A inclusão mais freqüente é de minerais do grupo do espinélio, que foram identificados por Hänni \& Kerez (1983). Apresentam-se de forma muito variada: desde pequenos grãos, distribuídos no cristal hospedeiro, ou até den- 
samente concentrados, formando "nuvens" que tornam a esmeralda praticamente opaca nessas regiões (Fotos $7 \mathrm{a}$ e Tb). A composição química determinada foi $\mathrm{Cr}_{2} \mathrm{O}_{3}(63,33 \%), \mathrm{FeO}+$ $\mathrm{Fe}_{2} \mathrm{O}_{3}(25,82 \%), \mathrm{Al}_{2} \mathrm{O}_{3}(6,68 \%), \mathrm{SiO}_{2}(3,32 \%$ - como contaminante), $\mathrm{MgO}(0,10 \%)$ e $\mathrm{NaO}(1,10 \%)$. Na realidade, trata-se de um espinélio com $\mathrm{Mg}$ e $\mathrm{Al}$ altamente substituídos por Fe e $\mathrm{Cr}$, respectivamente.
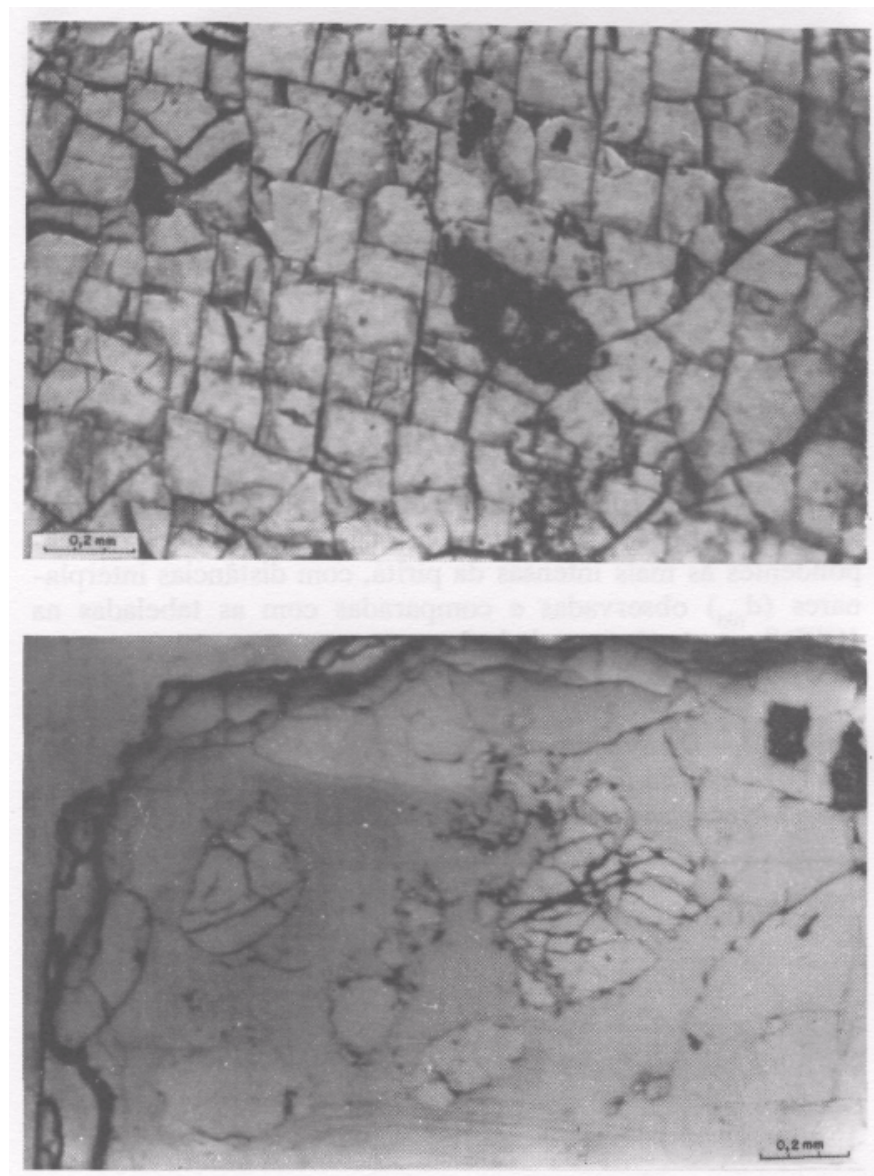

Foto 7 a e $7 b$-Esmeralda com inclusões de espinélio Photo $7 \mathrm{a}$ and $7 \mathrm{~b}-$ Emerald with picotite inclusions

Inclusões bifásicas (2-g) As inclusões fluidas são identificadas, em muitos casos, pela presença na cavidade de uma bolha de gás móvel.

$\mathrm{Na}$ maioria das amostras estudadas foram observadas inclusões tipo líquido-gás (2-g) com tamanhos variados (Foto 8a). Em algumas amostras, estão localizadas em fendas (Foto 8b) e, em outras, distribuídas quase uniformemente por todo o cristal de esmeralda.

RELAÇÃO ENTRE ROCHA ENCAIXANTE E INCLUSÕES O que pode ser observado neste conjunto de inclusões minerais, nas esmeraldas de Santa Terezinha de Goiás, é que elas foram formadas antes, durante e depois da cristalização do hospedeiro. O espinélio, por exemplo, é um dos primeiros minerais a se formar durante o resfriamento do magma. A foto $7 \mathrm{~b}$ mostra que o espinélio não foi apenas englobado pelo fluxo mineralizante do berilo, mas também interagiu ativamente com o mesmo. Como um dos resultados desta interação houve a deformação dos cristais de espinélio. O outro resultado foi a migração de cromo do espinélio para o berilo, originando, assim, a esmeralda.
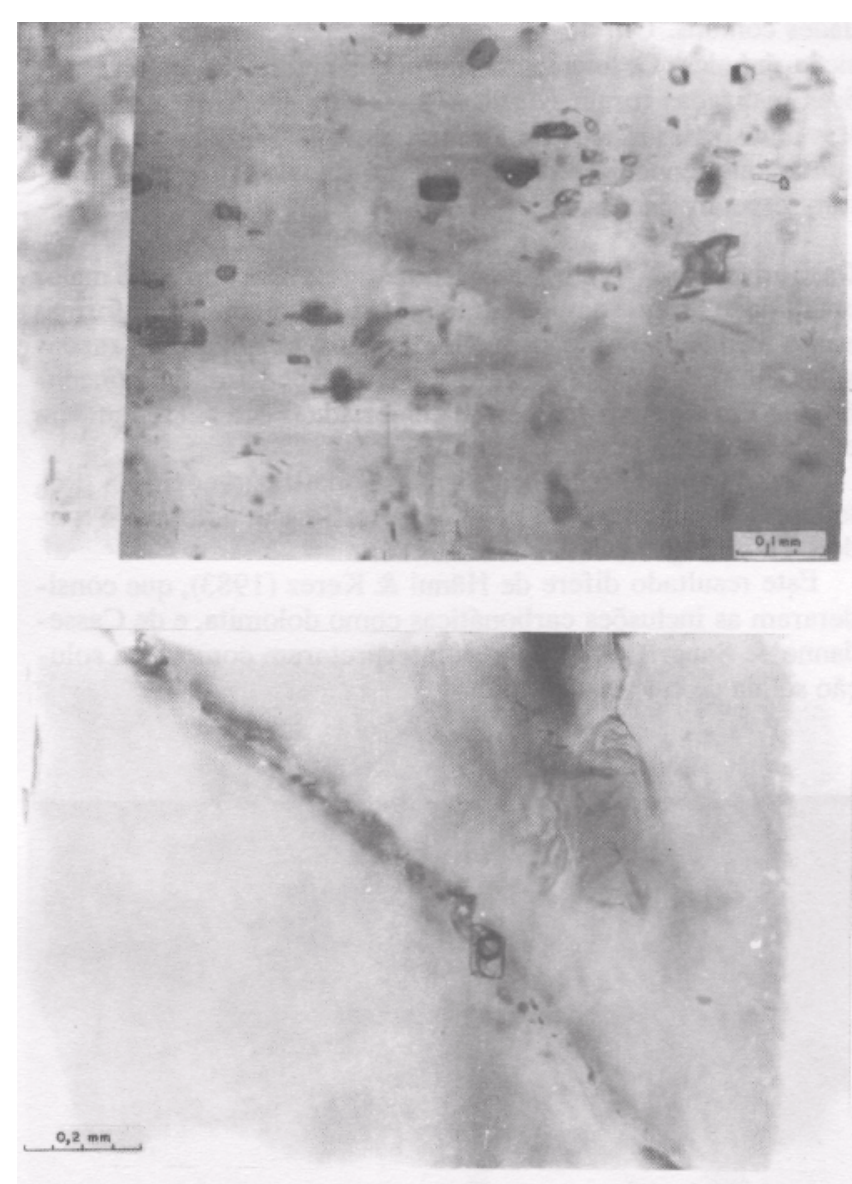

Foto 8 a e $8 b$-Esmeralda com inclusões bifásicas

Photo $8 \mathrm{a}$ and $8 \mathrm{~b}-$ Emerald with biphasic inclusions

Entre as inclusões de origem não-magmáticas encontradas foi notado mais de um período de formação, em relação à esmeralda. A foto 5 a mostra um carbonato singenético e a foto $5 \mathrm{~b}$ mostra um epigenético, preenchendo fendas do cristal hospedeiro.

A comparação dos minerais presentes nas rochas encaixantes com aqueles formando inclusões, nas esmeraldas de Santa Terezinha de Goiás, mostra, de forma geral, a conexão direta entre as duas associações. Quase todos os componentes que formam as mineralizações em veios ou bolsões, junto à esmeralda, apresentam-se também como minerais de inclusão. Além de pirita, talco, mica (biotita, flogopita), quartzo, pirrotita, carbonates (dolomita, siderita com Mg), halita e/ou silvita e rutilo (cuja formação pode acontecer sob condições variadas) é diagnóstica, em esmeraldas de Santa Terezinha de Goiás, a presença acentuada de espinélio. $\mathrm{O}$ aparecimento de substâncias carbonáticas nestas esmeraldas remonta às rochas encaixantes.

DISCUSSÃO E CONCLUSÃO As inclusões identificadas nos estudos realizados divergem, em parte, das encontradas por Sauer (1982), Cassedanne \& Sauer (1984), Hänni \& Kerez (1983), Schwarz \& Mendes (1985), Barros (1984) e Miyataefa/(198T).

Para Cassedanne \& Sauer (1984), por exemplo, as inclusões mais importantes nas esmeraldas de Santa Terezinha de Goiás são: pirita, cromita, talco e calcita, das quais a pirita é a mais freqüente. 
Neste trabalho, ao contrário, o espinélio foi encontrado como o mineral de inclusão de maior freqüência. A discrepância sobre o mineral mais freqüente resulta, provavelmente, do fato de que os pequenos cristais formadores das "nuvens" típicas foram vistos como pinta por Cassedanne \& Sauer (1984). Estas "nuvens" de minerais opacos, segundo os resultados aqui expostos, e em concordância com Hänni \& Kerez (1983) e Schwarz \& Mendes (1985), são quase exclusivamente de cristais de espinélio.

Foi observada, também, uma pequena discordância entre os pesquisadores com relação às inclusões de espinélio presentes nas esmeraldas. Para Cassedanne \& Sauer (1984) e Barros (1984), trata-se de cromita; para Miyata et al. (1987), de magnesioferrita ou magnesiocromita; para Hánni \& Kerez (1983), Schwarz \& Mendes (1985) e neste trabalho, no qual a conclusão foi feita a partir de análise química por microssonda eletrônica, essas "nuvens" são identificadas como espinélio.

Segundo Schwarz \& Mendes (1985), as inclusões bifásicas são raras e muito pequenas, enquanto os resultados aqui obtidos mostram que a maioria das amostras estudadas apresentam inclusões "2-g" com tamanhos e freqüências variadas. $\mathrm{O}$ número dessas inclusões é grande em algumas amostras.

Inclusões de rutílo, em esmeraldas do Estado de Goiás, tinham sido observadas somente nas provenientes do Garimpo da Fazenda das Lages (Leinz \& Leonardos 1959), e não tinham sido descritas, até o presente, nas de Santa Terezinha.

As inclusões minerais identificadas no presente trabalho, ou seja, espinélio, pirita, pirrotita, carbonates (dolomita, siderita com Mg), talco, talco-pirofilita, mica (biotita, flogopita), esmeralda, quartzo, rutilo, halita e/ou silvita e inclusões bifásicas, já foram citadas em outros trabalhos, exceto pirrotita, halita e/ou silvita, siderita com Mg (entre as carbonáticas) e talco-pirofilita.
As esmeraldas de Santa Terezinha de Goiás são, sob o ponto de vista de inclusões minerais, muito parecidas com as da Colômbia (Schwarz 1986), principalmente no que se refere à presença de pirita e carbonates. A presença de pirita tinha sido observada somente nas esmeraldas da Colômbia (Gubelin 1973) e Leysdorp (van Eeden et al. 1939). Em outras esmeraldas brasileiras (Socotó, Carnaíba-BA e Itabira-MG; Schwarz \& Mendes 1985), quase não se observam inclusões minerais.

As numerosas inclusões carbonáticas encontradas, de origens proto- e singenéticas, cuja presença não é compatível com a gênese puramente "pegmatítica", indicam que, durante o transporte de berílio e no decorrer da cristalização, as esmeraldas foram envolvidas por soluções carbonáticas. Esta hipótese é reforçada pela ausência de feldspatos, molibdenita, scheelita etc., minerais indicativos da presença de veios pegmatíticos. Assim, é possível que a origem das esmeraldas de Santa Terezinha de Goiás remonte a soluções da fase pneumatolítico-metassomática (Schwarz 1986 e Costa 1986), tendo, como fonte doadora de cromo, rochas básicas-ultrabásicas metamorfisadas (diversos xistos), cujo mineral cromífero é o espinélio, encontrado também como inclusão protogenética.

Agradecimentos Os autores agradecem ao Instituto de Geociências, Instituto de Física e Química de São Carlos, Faculdade de Farmácia e Odontologia de Ribeirão Preto, e ao Centro de Energia Nuclear na Agricultura - CENA (Piracicaba), todos pertencentes à USP, ao Instituto de Química de Araraquara - UNESP, pela utilização de seus laboratórios; e, à Universidade Federal de Goiás e à CAPES, que possibilitaram a realização deste trabalho pelo apoio financeiro concedido ao primeiro autor na forma de salário e bolsa de doutorado, respectivamente.

\section{REFERÊNCIAS BIBLIOGRÁFICAS}

BARBOSA, O.; BAPTISTA, M.B.; DYER, R.C.; BRAUN, O.P.G.; COTTA, J.C. 1969. Geologia e inventário dos recursos minerais do Projeto Brasília Petrópolis, DNPM/PROSPEC S.A. $225 \mathrm{p}$

BARROS, J.C. 1984, Relato ao Diretor do DNPM/VI-Ds. Com resultados parciais dos estudos das esmeraldas de Santa Terezinha de Goiás, desenvolvidos na Universidade de St. Andrews-Escócia. Goiânia, DNPM/VI Distrito Regional.

CASSEDANNE, J.P. \& SAUER, D.A. 1984. The Santa Terezinha de Goiás emerald deposit. Gems and Gemmology, 20:4-13.

COSTA, S.A.G. 1986. Correlação de seqüênncia encaixante das esmeraldas de Santa Terezinha de Goiás com os terrenos do tipo Greenstone Belt de Crixás e topologia dos depósitos. In: CONGR. BRAS. GEOL., 34, Goiânia, 1986. Anais... Goiânia, SBG. v.2, p. 597-614.

COUTO, P.A. \& ALMEIDA, J.T. 1982. Geologia e Mineralizacões na área do Garimpo de Carnaíba-BA. In: CONGR. BRÁS. GEOL., 32, Salvador, 1982, Anaís...Salvador, SBG. v.3, p.850-861.

DRAGO, V. A.; PINTO, A.C.; SIMÕES, M.A.; BEZERRA, P.E.L.; MONTALVÃO, R.M.G.; PRADO, P.; TASSINARI, C.C.G.; HILDRED, P.R. 1981. Geologia. In: MME - PROJETO RADAM BRASIL,F0//ia $S J$ ). 22 Goiás. Rio de Janeiro, DNPM. v.25, p.27-300.

GRIFFON, J.C.; KREMER, M.R.; MISI, A. 1967. Estudo estrutural e genético da Jazida de Esmeralda de Carnaíba-BA. An. Acad. bras. Ciên.39:150-161.

GUBELIN, E J. 1973. Internal World of Gemstones. Zurich, ABC Edition. $234 \mathrm{p}$

HÄNNI, H.A. \& KEREZ, C. J. 1983. Neues von Smaragd-Vorkommen von Santa Terezinha de Goiás-GO, Brasilien. Z. Dt. Gemmol. Ges. 32(1):50-58.

JOHNSON, P. W. 1961. The Chivor Emerald Mine. J. Gemm. 8: $126-152$

JOINT COMMUTES ON POWDER DIFFRACTION STANDARDS - JCPDS 1983. X-ray powder data file, card n 6-710, 13-558, 19-770,20-534. Philadelphia, JCPDS Publication.

LEINZ, V. \& LEONARDOS, O. H. 1959. Notas sobre as esmeraldas da Fazenda de Lages, Itaberaí-GO. Gemologia, 16: 7-14.
MIYATA, T.; HOSAKA, M.; CHIKAYAMA, A. 1987. On the inclusions in emerald from Santa Terezinha de Goiás-GO, Brazil. J. Gemm., 20(6):377-379.

POGUE. J.E. 1916. The emerald deposits of Muzo, Colômbia. Transactions American Institute of Mining e Minerallogical Enginneers, 55:810-834.

RIBEIRO, A. C. \& SÁ, W.L. 1983. Garimpos de esmeraldas de Santa Terezinha de Goiás-GO, In: DNPM. Garimpos do Brasil. Brasilia, DNPM. p.269-283. (Avulso 5).

RIBEIRO FILHO, W. 1978. Projeto Geologia da Região de Pilar Mara Rosa. Goiânia, DNPM/CPRM. v.l, 150p. (Rei. Int.).

RIBEIRO FILHO, W. 1981. Reavaliação da Geologia de Pilar-Mara. In: SIMP. GEOL. CENTRO-OESTE, 1981. Atas...Goiânia, SBG. D. 281-299.

RIBEIRO FILHO, W. \& LACERDA FILHO, J.V. 1985. Geologia da região de Santa Terezinha de Goiás. In: SIMP. GEOL. CENTRO-OESTE, 2, Goiânia. 1985. Atas...Goiânia, SBG. p. $174-184$.

SABÓIA, L. A. 1979. Os "Greenstone Belts" de Crixás e Goiás-GO. Goiânia, SBG/NCO. p.43-72. (Boi. Inf. 9).

SAUER, D. A. 1982. Emerald from Brazil. In: INTERNATIONAL GEMOLOGICAL SYMPOSIUM, Santa Mônica, 1982. Proceedings... Santa Monica, CA/GIA. p. 357-377.

SCHWARZ, D. 1986. Classificação genética das ocorrências de esmeralda. In: CONGR. BRAS. GEOL., 34, Goiânia, 1986. Anais... Goiânia ${ }_{2}$ SBG. v.4, p.1854-1862.

SOUZA, J. O. \& LEÃO NETO, R. 1984. Mapeamento Geológico na área de Garimpo de Santa Terezinha de Goiás. Goiânia, MME/DNPM/CPRM. 75p. (Rei. Int.)

VAN EEDEN, P. R. et al. 1939. The mineral deposit of Murchison range east of Leysdorp. Pretória, Geological Surrey Union of South África. 136 p. (Memoir 36).

MANUSCRITO A621 Recebido em 14 de setembro de 1989 Revisão do autor em 21 de junho de 1990 Revisão aceita em 21 de junho de 1990 